\title{
LINGUISTIK FORENSIK TERHADAP PERBUATAN TIDAK MENYENANGKAN DI MEDIA SOSIAL (KAJIAN PRAGMATIK)
}

\author{
Lilis Hartini ${ }^{1}$, Aceng Ruhendi Saifullah ${ }^{2}$, Dadang Sudana ${ }^{3}$ \\ Program Studi Linguistik, Universitas Pendidikan Indonesia \\ ${ }^{1}$ lilishartini90@gmail.com, ${ }^{2}$ acengruhendisaifullah@upi.edum, ${ }^{3}$ dsudana2013@yahoo.com
}

\begin{abstract}
Abstrak
Kesantunan merupakan aturan perilaku yang ditetapkan dan disepakati bersama oleh suatu masyarakat. Berbagai macam permasalahan sosial dapat dipicu oleh kurangnya kesantunan dalam berbahasa, berawal dari caci maki, kemudian berujung pada kekerasan fisik dan akhirnya mengakibatkan pelanggaran hukum, seperti perbuatan tidak menyenangkan. Permasalahan inti dalam penelitian ini adalah bagaimana parameter B\&L dalam menilai tindakan perbuatan tidak menyenangkan di media sosial dan situasi komunikasi yang bagaimana yang diperlukan dalam menciptakan kesantunan bahasa di media sosial. Penelitian ini bertujuan untuk mendeskripsikan tindakan perbuatan tidak menyenangkan di media sosial dan ketidaksantunan berbahasa yang digunakan penutur di media sosial yang berakibat pada tindakan hukum. Teori yang digunakan dalam penelitian ini adalah teori pragmatik tentang kesantunan berbahasa dari B\&L. Melalui metode kualitatif ditemukan bahwa media sosial merupakan sarana bergaulnya beragam komunitas sehingga tidak terlihat batasan kesantunan berbahasa maupun budaya berbahasa. Hasil penelitian menunjukkan bahwa terdapat tiga parameter kesantunan berbahasa yang dilanggar oleh netizen, yaitu skala peringkat jarak sosial, skala peringkat status sosial, dan skala peringkat tindak tutur, kemudian kesantunan berbahasa di media sosial sudah semakin luntur sehingga dipandang perlu untuk menyosialisasikan nilai kesantunan berbahasa B\&L.
\end{abstract}

Kata Kunci: Kesantunan berbahasa, media sosial, tindakan hukum

\begin{abstract}
Politeness is a behavior rule which is stipulated and agreed upon together by a group of community. Different various social problems can be triggered by the lack of politeness in using a language. It can start from scorn, lead to physical violence and end with violation of law, for example; unpleasant deed. The core problems of this research are; how the B\&L parameter assesses unpleasant deed in social media, and how communication situation is required in creating language politeness in social media. This research aims at describing the action of unpleasant deed in social media and language impoliteness used by the speaker in social media which causes legal action. The theory used in this research is pragmatics theory on language politeness by $B \& L$. Through this qualitative method, it can be found that social media is a means of getting along for different communities so there are no boundaries of language politeness and language culture. The result of this research shows that; there are three parameters of language politeness which are violated by netizens. They are social distance rating scale, social status rating scale, and speech act rating scale. Then, language politeness in social media has been fading away, so the socialization of language politeness $B \& L$ should be performed and applied.
\end{abstract}

Keywords: Language politeness; social media; legal action 


\section{PENDAHULUAN}

Pragmatik adalah salah satu cabang linguistik yang mempelajari ujaran dari penutur. Leech mengemukakan bahwa pragmatik adalah studi mengenai makna ujaran di dalam situasi-situasi tertentu atau dalam konteks tertentu. Dalam pragmatik terdapat prinsip-prinsip tentang bagaimana seorang manusia bertutur dalam situasi tertentu. Salah satu prinsip tersebut adalah prinsip kesantunan atau kesopanan. Dengan mengetahui prinsip-prinsip kesantunan kita sebagai penutur dapat menerapkan atau mengimplentasikan dalam situasi dan konteks tertentu dalam membuat tuturan (Leech, 1983).

Menurut (Levinson, 1983), pragmatics is the study of language usage. Definisi pragmatik dikemukakan juga oleh ahli lain, seperti sebelumnya dikemukakan oleh Harris \& Gregory (Harris, 1978), (Leech, 1993), Marcelo (Dascal, 1983). Sesudahnya dikemukakan oleh (Kasher, 1991), Jakob (Mey, 1993), (Yule, 2006), (Green, 1996), (Segerdahl, 1996), Cummings (1999), (Cruse, 2000), (Marmaridou, 2000), (Graham, 2007).

Sebagai sebuah fenomena pragmatik, kesantunan terletak bukan pada bentuk dan kata-kata, melainkan pada fungsi dan makna sosial yang diacu. Jika penutur mengatakan bentuk yang lebih sopan daripada konteks yang diperlukan, mitra tutur akan menduga bahwa ada maksud khusus yang tersembunyi. Sementara kesopansantunan atau etiket adalah tata cara, adat, atau kebiasaan yang berlaku dalam masyarakat. Istilah etiket atau tata krama dikemukakan oleh (Rachim, 1983), (Yudibrata, 1984), (Sudaryat, 2015). Kesantunan memperlihatkan sikap yang mengandung nilai sopan santun atau etiket dalam pergaulan sehari-hari.

Muslich (Vibriza dkk., 2017) membagi kesantunan dalam pergaulan sehari-hari menjadi tiga bagian. Pertama, ketika seseorang dikatakan santun, maka dalam dirinya tergambar nilai sopan santun atau nilai etiket yang berlaku secara baik di masyarakat tempat seseorang itu mengambil bagian sebagai anggotanya. Ketika dia dikatakan santun, masyarakat melabeli baik kepadanya, baik penilaian itu dilakukan secara seketika atau dalam jangka waktu yang lama. Penilaian dalam jangka waktu lama akan lebih mengekalkan nilai yang diberikan kepadanya. Kedua, kesantunan sangat kontekstual, yakni berlaku dalam masyarakat, tempat, atau situasi tertentu, tetapi belum tentu berlaku bagi masyarakat, tempat, atau situasi lain. Ketika seseorang bertemu dengan teman karib, boleh saja dia menggunakan kata yang agak kasar dengan suara keras, tetapi hal itu tidak santun ketika ditujukan kepada tamu atau seseorang yang baru dikenal. Mengecap atau mengunyah makanan dengan mulut berbunyi kurang sopan kalau sedang makan dengan orang banyak di sebuah perjamuan, tetapi hal itu tidak begitu dikatakan kurang sopan apabila dilakukan di rumah. Ketiga, kesantunan selalu bipolar, yaitu memiliki hubungan dua kutub, seperti antara anak dengan orang tua, antara orang yang masih muda dengan orang yang lebih tua, antara tuan rumah dengan tamu, antara pria dan wanita, antara murid dan guru, dan sebagainya. Keempat, kesantunan tercermin dalam cara berpakaian (berbusana), cara berbuat (bertindak), dan cara bertutur (berbahasa).

Kesantunan merupakan aturan perilaku yang ditetapkan dan disepakati bersama oleh suatu masyarakat tertentu sehingga kesantunan sekaligus menjadi prasyarat yang disepakati oleh perilaku sosial. Setiap anggota masyarakat percaya bahwa kesantunan yang diterapkan mencerminkan budaya suatu masyarakat. Ada pepatah yang sering kita dengar bahwa "bahasa menunjukkan bangsa". Bahkan dalam konteks individu bahasa dapat mencerminkan kepribadian seseorang. Karakter, watak, atau pribadi seseorang dapat diidentifikasi dari cara dia berbicara. Penggunaan bahasa yang halus, lemah lembut, 
sopan santun, sistematis, teratur, jelas, dan lugas mencerminkan pribadi penuturnya berbudi. Sebaliknya, penggunaan bahasa yang bersifat sarkastis, menghujat, memaki, mendiskreditkan, memprovokasi, mengejek, atau melecehkan akan mencitrakan pribadi yang kurang berbudi.

Ada beberapa model kesantunan bahasa yang dikemukakan para ahli dengan logika tiga dimensinya teori-teori kesantunan berbahasa (The Triadic Logic of Linguistic Politeness Theories), seperti Prinsip Saling Tenggang Rasa (Principle of Mutual Considerations/PMC) yang dikemukakan (Aziz, 2009)); (Lakoff, 1990) mengemukakan tentang Formalitas, Ketidaktegasan, dan Persamaan; Konsep Wajah yang dikemukakan K'ung Fu-Tzu; Prinsip kerja sama (Cooperative Principle) yang dikemukakan (Grice, 2004); Kesantunan bahasa dengan menggunakan muka mengacu kepada citra diri. Muka atau citra diri seseorang dapat jatuh. Oleh karena itu, muka perlu dijaga atau dilindungi. Agar muka tidak jatuh, muka perlu dijaga baik oleh pemilik muka itu sendiri maupun orang lain yang sedang berkomunikasi. Salah satu faktor yang berpotensi untuk menjatuhkan muka pelaku tutur adalah tindak tutur, tindak tutur perlu dilengkapi dengan peranti penyelamat muka yang berupa kesantunan berbahasa.

Kesantunan berkaitan dengan nosi "wajah negatif" dan "wajah positif". Wajah negatif terjadi ketika pendengar merasa "kehilangan muka" ketika mendengar tuturan, pembicara dapat merasa "terhina" dan "kehilangan harga diri". Wajah positif merupakan dambaan setiap orang yang terlibat komunikasi. B\&L mengemukakan bahwa setiap orang ingin agar nilai-nilai yang diyakini dihargai oleh orang lain sebagai suatu yang baik, menyenangkan, patut dihargai, menguntungkan, dan sebagainya. Dengan demikian, kesantunan selalu berkaitan dengan kepentingan pokok pendengar dalam tuturan (Brown \& Levinson, 1987)

Teori kesantunan ini diterapkan pada perbuatan tidak menyenangkan di media sosial. Oleh karena maraknya alat komunikasi di dunia maya (Virtual), salah satunya, berdampak pada pelanggaran hukum ketika alat komunikasi tersebut dijadikan ajang untuk saling menghujat, melecehkan, merundung, menghina, atau pun tindakan melawan hukum lainnya. Kejadian seperti ini direspons oleh pemerintahan dengan membuat aturan hukum di dunia maya dengan diterbitkannya UU ITE.

Dunia virtual adalah sarana komunikasi yang dijembatani oleh media elektronik dalam jaringan komputer dengan terhubung secara langsung (online). Komunikasi yang dilakukan bisa satu arah maupun dua arah atau timbal-balik. Hal ini disebabkan karakteristik dunia virtual itu dapat dilakukan secara langsung dengan chatting atau tidak langsung (ditunda). Ketika komunikasi yang bebas tanpa batas dilakukan langsung melalui chatting maka pengancaman muka akan terlihat langsung dengan menggunakan tanda-tanda nonverbal, seperti dengan cara membuat emoticon atau dengan cara berbicara kasar. Ketika hal ini masuk ke ruang publik di dalam grup terbuka maka akan berdampak pada tindakan hukum. Tindakan hukum ini akan bergulir ke arah proses hukum, ketika salah satu peserta tutur tersinggung dan melaporkan lawan tuturnya ke pihak yang berwajib (kepolisian) berupa perbuatan tidak menyenangkan di dunia maya (virtual).

Telah banyak kasus yang masuk ke ranah hukum dan berproses di pengadilan. Salah satunya adalah kasus pelanggaran hukum terhadap komunikasi di dunia virtual, yaitu perbuatan tidak menyenangkan. Perbuatan tidak menyenangkan adalah suatu tindakan yang menyebabkan orang lain merasa tidak nyaman, tidak senang, terganggu, marah, dan sebagainya. Dalam dunia hukum di Indonesia, perbuatan tidak menyenangkan diatur dalam Pasal 335 KUHP. Agar tidak menjadi korban peraturan tersebut, maka harus 
berperilaku baik, mengedepankan kesantunan berbahasa, dan menjauhi segala perbuatan yang melanggar hukum.

Perbuatan tidak menyenangkan sebetulnya akan terjadi apabila melakukan kegiatan komunikasi secara vulgar dengan orang lain, baik langsung maupun tidak langsung. Pada umumnya, Pasal 335 KUHP akan diberlakukan kepada orang-orang yang berkomunikasi secara verbal melalui media sosial.

Kasus perbuatan tidak menyenangkan dalam sosial media sering dihubungkan dengan UU ITE (Republik Indonesia, 2016), terutama Pasal 27 ayat 3 yang berisi tentang muatan penghinaan atau pencemaran nama baik. Begitu juga Pasal 28 yang berisi tentang menyebarkan kebencian. Seperti contoh (Gunawan, 2009) kasus Farah yang divonis penjara karena kasus penghinaan melalui jejaring sosial Facebook terhadap Felli dengan kalimat berikut:

"Hai anjing lu nggak usah ikut campur gendut. Kayak tante-tante enggak bisa gaya, emang lu siapa. Urus saja diri lu yang jelek kayak babi. Sok cantik enggak bisa gaya belagu. Nyokap lu nggak sanggup beliin baju buat gaya. Makanya lu punya gaya gendut. Pantat besar lu kayak bagus aja. Emang lu siapanya UJ. Hai gendut bangsat ya lu anjing."

Kasus ini mengemuka karena kecemburuan yang diungkapkan lewat jejaring sosial sehingga mengakibatkan terjeratnya hukum. Kasus seperti ini tidak akan terjadi apabila generasi muda diajarkan etika oleh orang tua dan guru. Bukankah Indonesia terkenal dengan budaya yang santun dan pandai menghargai orang? Budaya ini harus digali kembali sebagai kearifan lokal bagi bangsa Indonesia.

Adanya bermacam-macam komunikasi yang kebablasan ini sangat meresahkan sebagian besar masyarakat. Oleh karena, budaya malu seakan-akan sudah tidak diperhatikan lagi oleh generasi sekarang. Etika dan moral sudah luntur dengan pesatnya alat komunikasi lewat dunia maya ini. Berdasarkan hal tersebut, peneliti tertarik untuk meneliti kesantunan bahasa yang ada di media sosial. Penelitian dibatasi pada kasus penghinaan di jejaring sosial Facebook, Tweeter, Kaskus, Line, whatsApp, atau Instragram.

Berdasarkan latar belakang di atas, masalah utama dalam penelitian ini adalah bagaimana parameter B\&L dalam menilai tindakan perbuatan tidak menyenangkan dalam media sosial dan bagaimana situasi komunikasi yang diperlukan dalam menciptaan kesantunan berbahasa. Adapun tujuan penelitian ini adalah untuk menyosialisasikan parameter B\&L dalam menilai tindakan perbuatan tidak menyenangkan di media sosial dan untuk mendeskripsikan situasi komunikasi yang diperlukan dalam menciptaan kesantunan berbahasa.

\section{METODE PENELITIAN}

Metode yang dipilih dan digunakan dalam mendeskripsikan permasalahan penelitian adalah metode deskriptif, yaitu metode yang menggambarkan objek yang diteliti secara apa adanya. Tujuannya adalah menggambarkan secara sistematis, fakta dan karakteristik objek yang diteliti dengan tepat. Sementara, guna menjawab masalah penelitian yang sudah ditetapkan, peneliti memilih pendekatan kualitatif. Pendekatan kualitatif menekankan pada deskripsi tekstual atau fenomena yang diteliti.

\section{HASIL DAN PEMBAHASAN}

Parameter B\&L dalam menilai perbuatan tidak menyenangkan di media sosial 
a. Skala peringkat jarak sosial antara penutur dan mitra tutur (social distance between speaker and hearer)

Temuan (1) diambil dari salah satu iklan multivitamin:

$X:$ "Excuse me"

$Y:$ "Apa sih?"

X: "Oh maaf saya kira Bapak ga bisa bahasa Indonesia. Itu!" (menuntuk tulisan harap antri)

Skala ini banyak ditentukan oleh parameter perbedaan di dalam hal umur, jenis kelamin, dan latar belakang sosiokultural seseorang. Dalam data dideskripsikan bahwa seorang anak (X) berbicara santun kepada seorang pria dewasa (Y) karena tidak mau antre ketika akan membeli tiket. Y malah bertanya dengan nada tinggi karena merasa terganggu dengan pertanyaan si anak. Latar belakang sosiokultural seseorang memiliki peran yang sangat besar dalam menentukan peringkat kesantunan yang dimilikinya. X sejak kecil sudah diajarkan santun kepada orang yang lebih tua sehingga bahasa yang diungkapkan menunjukkan kesantunan bahasa.

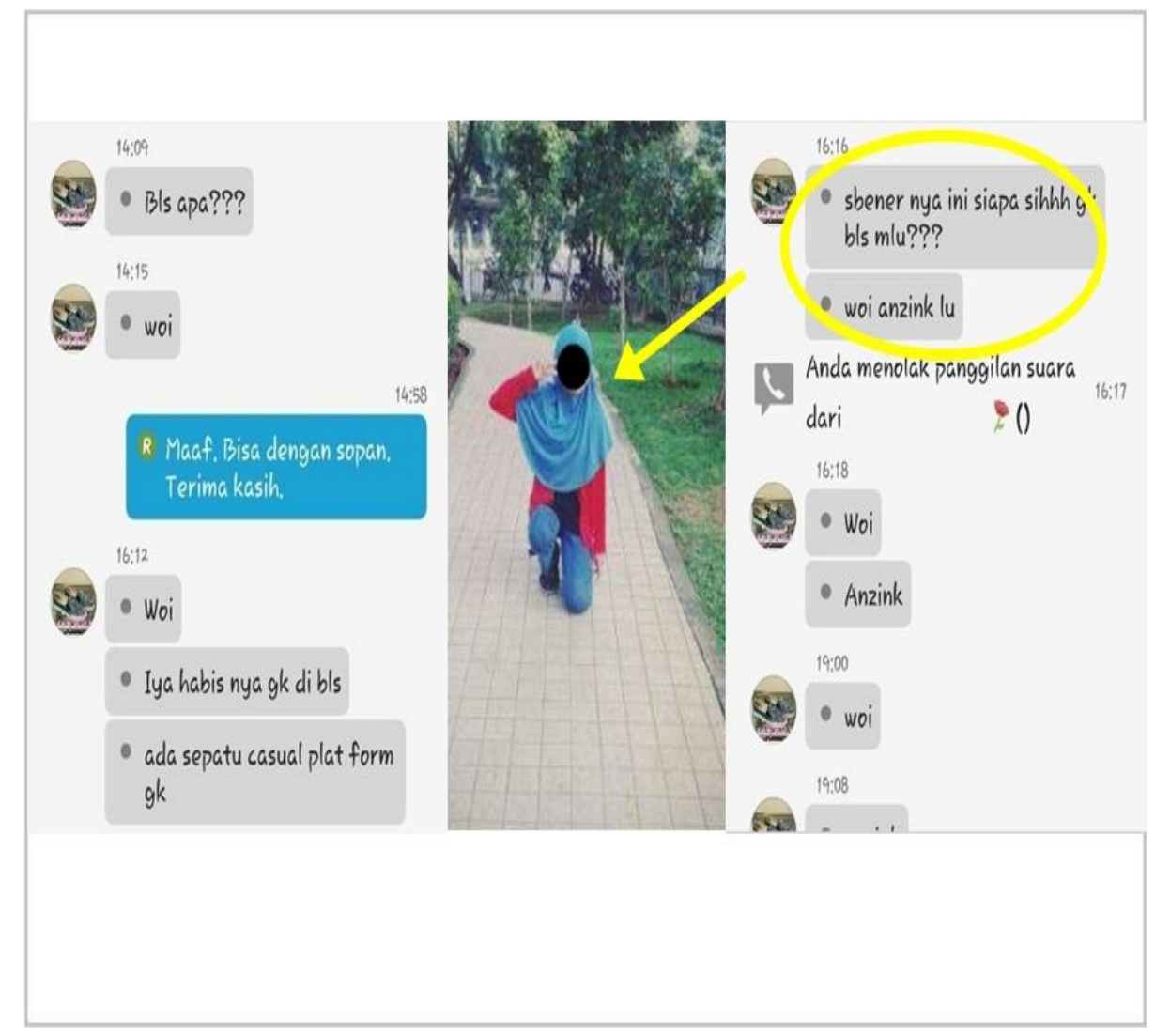

Gambar 1 Temuan diambil dari online shop (Brilio.Net, 2016)

Berbeda dengan X, remaja ini begitu vulgar, kata-kata yang diucapkan kasar, tidak santun, dan tidak menghargai orang yang lebih tua darinya, padahal orang yang diajak bicara sudah cukup sabar menanggapinya. Ketidaksantunan berbahasa dari remaja ini berdampak pada disebarluaskannya posting-an kata-kata kasarnya ke media sosial. Dengan harapan dia lebih berhati-hati dalam berbicara di media sosial. Hal ini pun akan menjadi contoh bagi para remaja lainnya. 
Berdasarkan kasus di atas, parameternya adalah perbedaan usia antara si penutur dan mitra tutur. Didapat kenyataan bahwa orang yang berjenis kelamin wanita, lazimnya memiliki peringkat kesantunan yang lebih tinggi dibandingkan dengan orang yang berjenis kelamin pria. Begitu juga sebaliknya, semakin tua umur seseorang maka peringkat kesantunan dalam bertuturnya akan menjadi semakin tinggi.

b. Skala peringkat status sosial antara penutur dan mitra tutur (the speaker and hearer relative power)

Skala pengukuran kesantunan ini didasarkan pada kedudukan asimetris antara si penutur dan mitra tutur. Berikut temuannya.

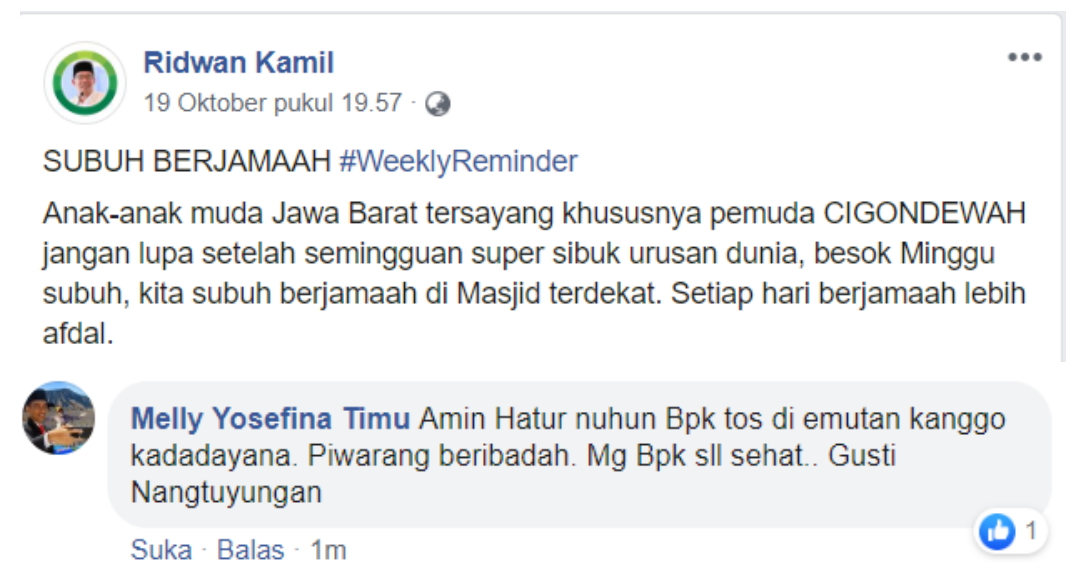

Gambar 2 Temuan diambil facebook (Kamil, 2019)

c. Skala peringkat tindak tutur atau tindak ujar (rank rating)

Skala kesantunan berbahasa ini didasarkan atas kedudukan relatif tindak tutur yang satu dengan yang lainnya di dalam sebuah praktik pertuturan yang sesungguhnya. Kesantunan dan kesopanan berbahasa amat erat kaitannya dengan kaidah berbahasa yang selaras dengan norma social dan budaya yang berlaku dalam masyarakat atau komunitas pengguna bahasa.

Temuan: slogan pesepakbolaan di Indonesia. Kota Bandung mempunyai klub sepak bola yang melekat di hati masyarakatnya, yaitu Persib. Dua slogan Persib berikut mewakili masyarakat Jawa Barat pada umumnya

1) Viking 27 Brother Home: Eleh meunang teu paduli teuing nepi paeh PERSIB nu aing. ('Menang atau kalah tidak peduli sampai mati PERSIB punyaku')

2) Viking SMAN 5 Cimahi: Borojol jang PERSIB ('Lahir untuk PERSIB')

Bagi orang Jawa Barat bahasa kasar yang ditulis dalam slogan itu tidak menjadi masalah. Bahkan mereka merasa bangga karena slogan tersebut sudah mendarah daging pada jiwa masyarakat Jawa Barat. Begitu juga bila kalimat seperti itu dikomunikasikan oleh orang yang sudah akrab, maka tidak ada nada yang tersinggung. Akan tetapi, jika kata borojol, misalnya, diucapkan oleh orang muda kepada orang yang lebih tua maka kalimat yang tersusun menjadi tidak santun. Misalnya:

1) Teman akrab atau sahabat:

A: "aing tadi geus ngaborojolkeun taeun euy." ("tadi aku sudah keluarin anu $[B A B]$ ') 


\section{B: “Aing oge sarua." ('aku juga sama')}

2) Anak kepada orang tua:

A: "aing tadi geus ngaborojolkeun taeun euy." ('tadi aku sudah keluarin anu [BAB]')

C: "Sing sopan atuh ari nyarios ka sepuh, teu kenging kitu." ('Bicara yang sopan $\left.y a^{\prime}\right)$

Bagaimana dengan seorang netizen yang kata-katanya melecehkan suatu daerah? Florence adalah seorang mahasiswa notariat di Yogyakarta karena merasa kesal mengantre di pom bensin dia pun mengekspos kata-kata vulgar di media sosial. Florence sudah melakukan tindakan perbuatan tidak menyenangkan bagi masyarakat Yogyakarta. Posting-an tersebut berakibat ke ranah hukum karena tidak santun. Masyarakat Yogyakarta merasa tersinggung atas penghinaan Florence sehingga dia dilaporkan ke kepolisian. Berikut adalah temuan dalam(Gultom, 2014):

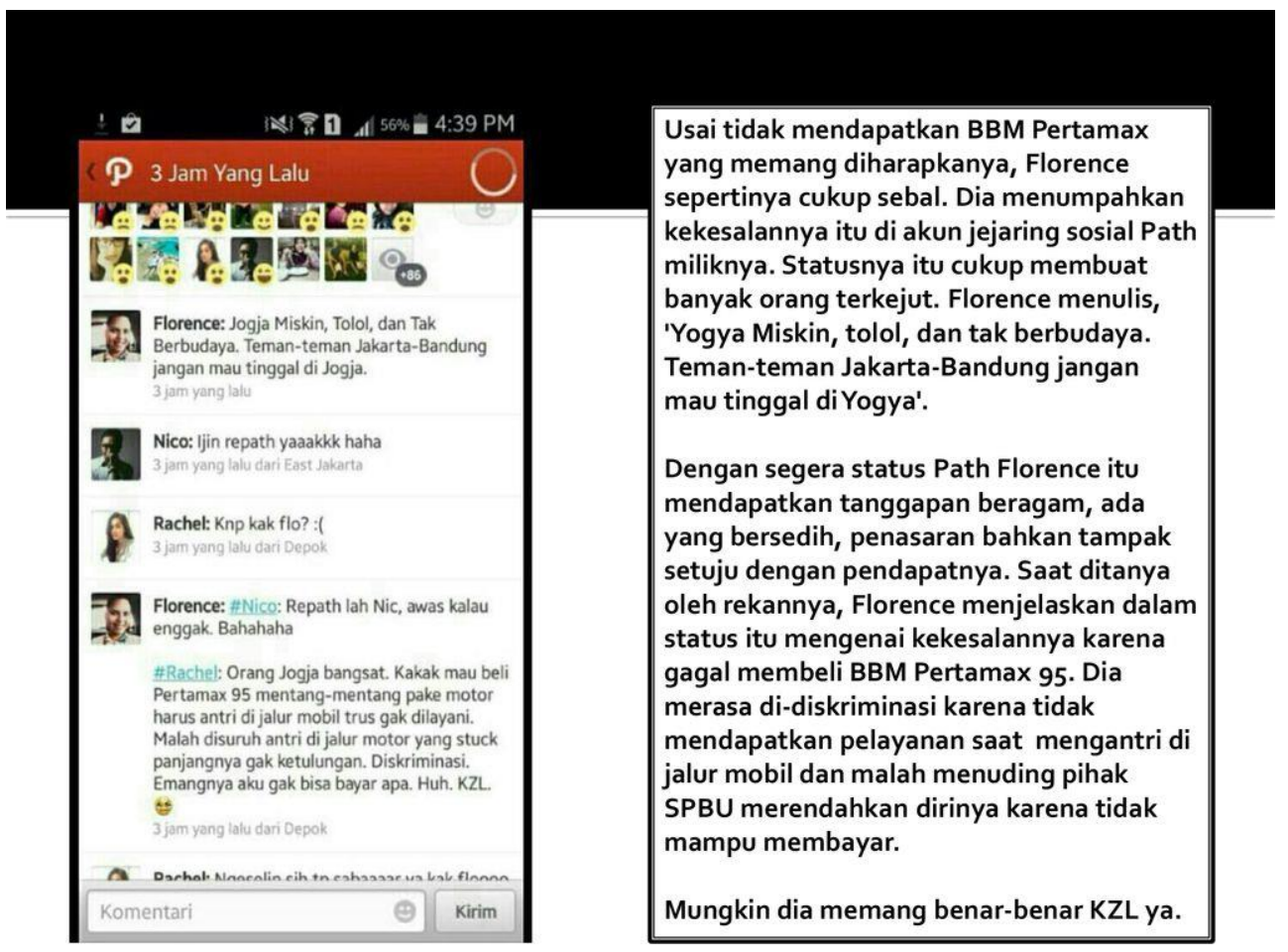

Gambar 3 Temuan diambil dari www.gultomlawconsultants.com

Kasus Florence ini termasuk melanggar Pasal 335 KUHP dan baru-baru saja dia divonis dua bulan penjara dan denda Rp. 10.000.000.

\section{Situasi komunikasi yang diperlukan dalam penciptaan kesantunan berbahasa}

a. Muka (wajah) Positif

Wajah dengan keinginan positf terkait dengan nilai solidaritas, ketakformalan, pengakuan, dan kesetiakawanan. Muka positif lebih mengarah kepada keinginan setiap orang untuk menyenangkan orang lain.

Temuan:

Kang Cecep, seorang OB asal Bogor nekad bangun sekolah di desanya. 
Bantu kang Cecep di https://kitabisa.com/bantuobbangunsekolah

Komentar:

Kitabisa.com: Halo semuanya! Terima kasih atas respond an sharenya

Fina Silv: Transfernya ke mana ya kalau mau donasi?

Rahman: Bisa minta alamat lengkapnya?

Rio Descrapria: Semangat kang!

Data di atas menunjukkan muka positif dari semua peserta tutur. Pertama, ketika kitabisa.com mem-posting tentang OB yang membangun sekolah dan menghimbau netizen untuk menyumbang, respons yang didapat cukup banyak. Kitabisa.com sebagai admin berusaha untuk mengakrabkan diri menyapa dengan menggunakan kalimat "Halo semuanya! Terima kasih atas respons dan sharenya." Rasa solidaritas atau dukungan netizen bisa membuat cita-cita kang Cecep menjadi kenyataan. Kedua, bagi kang Cecep membuat sekolah adalah suatu kepuasan batin karena bisa membantu orang-orang yang tidak mampu secara finansial. Ketiga, bagi netizen membantu sesame adalah kewajiban dan dapat menyenangkan hati orang lain.

Komunikasi di atas memenuhi unsur kesantunan berbahasa dengan muka positif karena semua pelaku komunikasi menggunakan kalimat yang lugas, apa adanya atau tidak dibuat-buat (ketakformalan). Dukungan positif dari para netizen merupakan pengakuan terhadap sepak terjang OB Cecep. Solidaritas dan kesetiakawanan yang terjalin dalam bahasa santun tercermin dari komentarkomentarnya.

b. Muka (Wajah) Negatif

Wajah dengan keinginan negatif bermuara pada keinginan seseorang untuk tetap mandiri, bebas dari gangguan pihak luar, dan adanya penghormatan pihak luar terhadap kemandiriannya itu. Muka negatif mengacu pada keinginan setiap orang untuk tidak dihalangi oleh siapa pun dalam bertindak.

Setiap perbuatan yang bertentangan dengan muka (wajah) yang diinginkan oleh petutur dan mitra tutur termasuk dalam tindakan mengancam muka. Tindakan mengancam muka ini menunjukkan bahwa penutur ingin mitra tutur melakukan sebuah tindakan tertentu.

Temuan dalam(Tribun, 2017), seorang netizen berkata-kata tidak sopan pada polisi sehingga dia diperkarakan pihak kepolisian karena telah melakukan pencemaran tertulis sehingga melanggar pasal 335 ayat (2) tentang perbuatan tidak menyenangkan. 

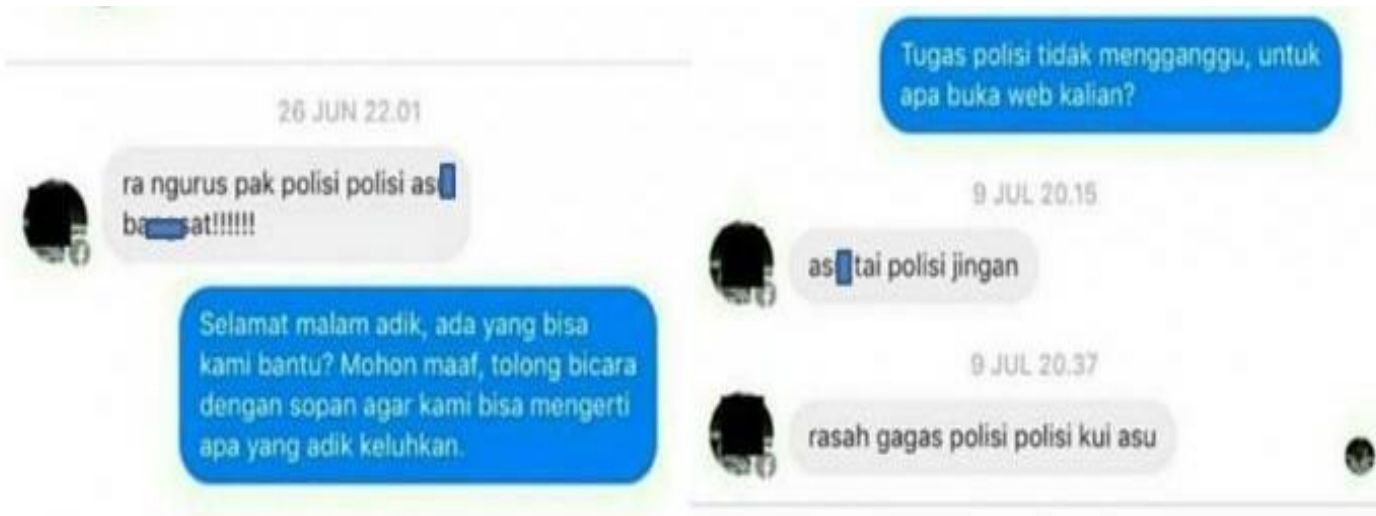

Gambar 4 Temuan Tribun.com

Menurut (Yule, 2006) dalam interaksi sosial, orang biasanya bertingkah laku seolah-olah harapan mereka berkenaan dengan nama baik atau keinginan wajahnya akan dihormati. Jika seorang penutur menyatakan sesuatu yang mengandung ancaman terhadap nama baiknya (dalam hal ini nama baik kepolisian) maka pernyataan Ganjoel dideskripsikan sebagai tindak ancaman wajah.

Pengancaman muka negatif berupa cacian, makian, bahkan hujatan yang dilakukan seorang anak ini dimasukkan ke dalam pengancaman muka negatif karena polisi menanggapinya dengan mengambil jarak aman atau menjaga wibawa kepolisian dengan keinginan anak tersebut menjadi segan dan sikapnya menjadi santun. Akan tetapi, anak tersebut tetap berperilaku tidak santun sehingga pihak kepolisian mengambil tindakan hukum untuk menyelamatkan wajah.

\section{SIMPULAN}

Parameter kesantunan diwujudkan dengan skala pengukur peringkat kesantunan. Berdasarkan temuan yang dianalisis ternyata latar belakang sosiokultural seseorang memiliki peran yang sangat besar dalam menentukan peringkat kesantunan yang dimilikinya; Perilaku yang menonjolkan ketidaksantunan berakibat pada suasana komunikasi yang akan menimbulkan konflik. Suasana konflik di media sosial dilatarbelakangi oleh perbedaan ciri-ciri yang dibawa individu dalam suatu interaksi, seperti ciri fisik, kepandaian, pengetahuan, adat istiadat, dan keyakinan. Semua ciri itu jika tidak dikendalikan akan mengakibatkan perbuatan tidak menyenangkan dalam berkomunikasi karena di dalamnya terdapat hujatan, hinaan, perundungan; Beberapa bentuk ketidaksantunan dalam berkomunikasi di media sosial berdampak pada diberlakukannya hukum karena perbuatan tidak menyenangkan dari penutur maupun lawan tutur, seperti saling melaporkan ke pihak kepolisian dengan menggunakan pasal 335 KUHP atau UU ITE. Inilah parameter ketidaksantunan yang berlaku di media sosial. Situasi komunikasi yang diperlukan dalam menciptakan kesantunan berbahasa dengan menggunakan kalimat yang lugas atau tidak dibuat-buat agar wajah yang sudah bernilai positif dan wajah yang bernilai negatif tetap terjaga dengan menggunakan pola bahasa yang santun, yang tidak merusak nilai-nilai wajah; Penggunaan bahasa verbal dan nonverbal di media sosial harus diperhatikan agar komunikasi yang tercipta tidak menimbulkan kesalahpahaman dan ketersinggungan, yang dapat berdampak pada tindakan hukum. 


\section{DAFTAR PUSTAKA}

Aziz, E. A. (2009). Tiga dimensi kesantunan berbahasa: Tinjauan terkini. KIMLI. Retrieved from https://lib.atmajaya.ac.id/default.aspx?tabID=61\&src=a\&id=199728

Brilio.Net. (2016). Percakapan tidak sopan remaja di online shop. Retrieved from https://www.brilio.net/news/percakapan-tak-sopan-remaja-ke-penjual-online-inibikin-naik-darah-160121

Brown, P., \& Levinson, S. (1987). Politeness: Some universals in language usage. In Cambridge University Press. https://doi.org/10.2307/3587263

Cruse, A. (2000). Meaning in language: An introduction to semantics and pragmatics. Oxford: Oxford University Press.

Dascal, M. (1983). Pragmatics and the philosophy of mind. Amsterdam: John Benyamin.

Graham, S. L. (2007). Disagreeing to agree: Conflict, (im) politeness and identity in a computer-mediated community. Journal of Pragmatics. https://doi.org/10.1016/j.pragma.2006.11.017

Green, G. M. (1996). Pragmatics and natural language understanding. Mahwah, NJ: Erlbarum.

Grice. (2004). Logic and conversation. Syntax and Semantics, (January), 41-58.

Gultom. (2014). Penghinaan terhadap Kota Yogyakarta. Retrieved from https://i2.wp.com/www.gultomlawconsultants.com/wpcontent/uploads/2014/09/Florence-Benci-Jogja.jpg?resize $=620 \% 2 \mathrm{C} 355$

Gunawan, E. (2009). Penghinaan di Facebook bermotif cinta segitiga. Retrieved from Okezone.com

Harris, R., \& G. E. M. (1978). Psycology of pragmatic implication: Information processing between the lines. Journal of Experimental Psycology: General, 107: $1,1-22$.

Republik Indonesia. (2016). Undang-undang informasi dan transaksi elektronik. Jakarta: Gramedia.

Kamil, R. (2019). Subuh berjamaah. Retrieved from www.facebook.com

Kasher, A. (1991). Pragmatics and the modularity of mind. In S. Davis (Ed.), Pragmatics: A. Reader. New York: Oxford University Press.

Lakoff, R. T. (1990). Talking about language. Talking power. USA: Basic Book.

Leech, G. N. (1993). Principles of pragmatics. London: Longman. 
Levinson, S. (1983). Pragmatics. Cambridge: Cambridge University Press.

Marmaridou, S. S. A. (2000). Pragmatic meaning and cognition. Amsterdam: John Benyamin.

Mey, J. L. (1993). [Jacob_Mey] Pragmatics_an_introduction_(2nd_ed) (b-ok.org).pdf https://books.google.co.id/books/about/Pragmatics.html?id=TT_TF4sM6lcC\&re dir_esc=y\%0Ahttp://dlx.bok.org/genesis/615000/65cf48ea94750adac474d87f59 94986b/_as/\%5BJacob_Mey\%5D_Pragmatics_An_Introduction_(2nd_ed)(bok.org).pdf

Rachim. (1983). Etiket dan pergaulan. Jakarta: PT. Karya Nusantara.

Saifullah, A. R. (2019). Semiotik dan kajian wacana interaktif di internet. Bandung: UPI Press.

Segerdahl, P. (1996). Language use: A philosophical investigation into the basic notions of pragmatics. Suffolk, UK: McMillan Press Ltd.

Sudaryat. (2015). Wawasan kesundaan. Bandung: JPBD FPBS UPI.

Tribun. (2017). Bocah memaki polisi di medsos. www.tribun.com.

Vibriza, J., Rahadi, D. R., Marwan, M. R., \& Ahyad. (2017). Perilaku pengguna dan informasi. Jurnal Gunadarma, 4(1), 192-208. https://doi.org/https://doi.org/10.22146/jps.v4i2.28586

Yudibrata. (1984). Bagbagan makena basa. Bandung: CV. Geger Sunten.

Yule, G. (2006). Pragmatik (I; I. F. Wahyuni, Ed.). Yogyakarta: Pustaka Pelajar. 